\title{
Abordagens na formação de professores: \\ uma reconstrução aproximativa do campo conceitual
}

CATIA PICCOLO VIERO DEVECHI

Universidade de Brasília

AMARILDO LUIZ TREVISAN Universidade Federal de Santa Maria

"A despeito de o Logos ser comum a todos, o vulgo vive como se cada um tivesse um entendimento particular"

Heráclito, Fr. 2

\section{CONSIDERAÇÕES INICIAIS}

A preocupação com a discussão sobre a formação de professores está presente não só entre os profissionais da educação, mas também entre profissionais de outras áreas e/ou pessoas comuns que apostam na educação como alternativa para a solução dos problemas sociais, culturais e consequentemente para o desenvolvimento do país. Há uma emergente solicitação da sociedade, não para disciplinar ou regrar a formação, mas para torná-la fonte de educação de qualidade diante das demandas oriundas dos interesses e necessidades do momento. Espera-se uma formação que ofereça ao professor atitude de confiança e responsabilidade, capaz de garantir o enfrentamento das contingências do mundo. Em se tratando do Brasil, em que essas contingências são explícitas, os problemas surgem de todas as partes, tornando o tratamento do tema cada vez mais complexo e diversificado. As 
discussões acontecem de múltiplas formas, com o objetivo de dar conta dos contextos e das particularidades locais ou regionais. Trata-se de um desejo justificável de equacionar as questões mais emergenciais, de tal modo que tem desencadeado um crescimento de propostas e modelos formativos. Mas, diante do expressivo incremento das diversas propostas, surgem algumas questões inevitáveis: buscamos uma formação que contribua para a almejada educação de qualidade para todos ou para satisfazer anseios de grupos específicos? Ou, ainda, é possível atender aos contextos singulares sem descaracterizar o objetivo de uma educação de qualidade para todos? Como pensar atualmente a relação entre singularidade e totalidade na formação do professor?

É regra corrente que, a partir da crítica ao cientificismo tradicional levantada por inúmeros autores, entre eles, sobretudo, os pós-positivistas e frankfurtianos, a produção científica na educação passou a ser realizada por distintas e, às vezes, por confundidas abordagens epistemológicas. Algumas se destacam mais que outras; esse parece ser o caso das pós-positivistas, as fenomenológico-hermenêuticas, as dialéticas e as pós-estruturalistas, que parecem vigorar entre as abordagens mais utilizadas no campo da formação de professores no Brasil. As pós-positivistas, alicerçadas principalmente na teoria hipotético-dedutiva de Popper, na sociologia de Dürkhein e na teoria dos jogos de linguagem de Wittgenstein, dedicam-se a alcançar explicações científicas por meio da tentativa de refutação ou confirmação de hipóteses, apostando na autonomia do jogo de linguagem ou da proposição que define a tarefa do professor em relação ao mundo circundante e/ou às relações com os sujeitos que o produzem. As fenomenológico-hermenêuticas, na linha de Husserl, Heidegger, Gadamer, Merleau-Ponty, Paul Ricoeur e Sartre, empenham-se em incentivar a busca da compreensão dos fenômenos educativos por meio de narrativas que visam à sua descrição sistemática pelo docente e à interpretação constante. As dialéticas, desde Marx, Lukács, Gramsci e frankfurtianos, apegam-se à necessidade de o professor desenvolver novas sínteses no confronto entre seu pensamento e o real vivido no contexto social, num processo crítico e transformador da natureza e da sociedade. Já as pós-estruturalistas, baseadas em Nietzsche, Foucault, Derrida e Deleuze-Guattari, chamam atenção para a inserção do discurso da docência no universo efêmero e fragmentário do cotidiano pedagógico, atravessado por múltiplas determinações (ou subjetivações) de poder, gênero, classe, etnia, orientação sexual e cultural. É claro que toda classificação é suscetível de crítica por incorrer facilmente em arbitrariedade, ainda mais levando em conta o amplo leque de opções que envolve autores e correntes tão diversificados. Além disso, tais movimentos teóricos e seus expoentes não são estanques, sendo que muitos discursos da formação incorporam diferentes referenciais. Alguns deles atualmente cruzam posições hermenêuticas e fenomenológicas com as pós-estruturalistas, por exemplo, originando diferentes narrativas culturais (autobiográficas ou não) de gênero, etnia, sexo, classe,etc. Outros buscam forças nas contribuições da analítica e do pós-positivismo para manter um 
olhar marxista sobre a formação, concebido a partir de dados concretos da realidade, gestando uma formação científica abalizada pela pesquisa empírica.

Os cruzamentos, no entanto, são exceções; a regra é o isolamento entre as correntes, o que torna os enfrentamentos muito comuns. Apesar de compartilharem da crítica à neutralidade do positivismo clássico, da compreensão de que não é possível ao professor alcançar saberes absolutos, mas saberes provisórios, sempre suscetíveis de modificações, na participação teórica nas investigações, as diferentes abordagens de cunho qualitativo têm desencadeado diversos conflitos na discussão epistemológica da área. Podemos aludir aos confrontos mais eminentes, que são: racionalidade versus racionalidades ou emotividade, objetividade natural versus objetividade linguística, previsibilidade versus imprevisibilidade, universalidade versus probabilidade ou singularidade, causalidade objetiva versus causalidade texto/contexto ou totalidade/partes, explicação versus compreensão, centralidade no sujeito, no objeto ou na contraposição entre ambos. Trata-se de destacadas desavenças no que se refere à produção e legitimação dos saberes da área da educação, que a têm "transformado, por vezes, mais num palco de lutas autodestrutivas do que propriamente num ambiente de saudável convívio democrático” (Devechi; Trevisan, 2010, p. 149). Prova disso é que, nos últimos tempos, tem imperado em educação não uma sucessão histórica de paradigmas teóricos, mas uma coexistência de abordagens teórico-metodológicas que permitem tratar os problemas referentes aos processos formativos de múltiplas maneiras, cabendo a cada pesquisador identificar o modo de teorizar que considera mais confiável.

Este artigo pretende discutir outra abordagem que já vem sendo utilizada por investigadores, especialmente no campo da filosofia da educação, ${ }^{1}$ porém ainda não muito teorizada na área específica da formação de professores: a hermenêutica reconstrutiva. Ela segue a fundamentação dos propósitos da racionalidade comunicativa, que aposta na legitimação de saberes por meio de acordos "que depende de tomadas de postura de afirmación o negación, frente a pretensiones de validez que potencialmente se apoyan en razones" (Habermas, 2003a, p. 152). No objetivo dessa proposta não está somente a vontade de aperfeiçoar os saberes da área e nem exclusivamente a melhoria dos índices ou dos resultados das exigências governamentais, o que por si já seria suficiente para justificar o investimento da pesquisa. Deseja-se, sobretudo, sugerir a correção de eventuais desvios ocasionados pelas formas anteriores de tratamento do problema, que acabaram possibilitando o surgimento de três grandes manifestações nesse campo: investigação sobre formação de

1 Exemplos nesse sentido são os trabalhos de: M. O. Marques, Educação/interlocução, aprendizagem/reconstrução de saberes, UNIJUI, 1996; N. H. Hermann, Educação e racionalidades: conexões e possibilidades de uma razão comunicativa na escola, Porto Alegre: EDIPUCRS, 1996; A. L. Trevisan. Filosofia da educação: mímesis e razão comunicativa, UNIJUÍ, 2000; R. I. Bannel, Habermas e a educação, Autêntica, 2006. 
professores, investigação $\mathrm{em}$ formação de professores e investigação para a formação de professores. ${ }^{2}$ Diferentemente, a posição da hermenêutica reconstrutiva diante do objeto da formação pode ser entendida como uma investigação com a formação de professores, consentindo pensar sua compreensão como forma comunicativa de alcançar argumentos válidos. Esses são constituídos com a finalidade de valorizar proferimentos que, partindo do empírico, pretendem alcançar saberes cada vez mais amplos ou universais.

\section{DIAGNÓSTICO DA FORMAÇÃO NA PLURALIDADE DE PERSPECTIVAS TEÓRICAS}

Alguns pesquisadores da educação têm apontado como um dos grandes problemas da investigação na área da formação de professores o fato de que, apesar do incremento cada vez maior de pesquisas, pouco se tem avançado na discussão nos últimos tempos. Quatro importantes causas têm sido indicadas para explicar esse fenômeno: falta de memória, despreocupação com a avaliação da legitimidade das pesquisas, falta de diálogo entre as diferentes perspectivas teóricas e despreocupação com a totalidade. A falta de memória é uma preocupação apontada por Bernard Charlot, no sentido de que não são levadas em consideração pesquisas realizadas em outros momentos da história. Ao tratar da pesquisa em educação, que serve para as investigações sobre formação de professores, "refazemos continuadamente as mesmas teses, as mesmas dissertações, sem sabermos o que foi produzido anteriormente" (Charlot, 2006, p. 9).

Apoiado em Cunha, Alves-Mazzotti (2001, p. 4) indica outra dificuldade: a falta de seriedade das avaliações dos resultados das pesquisas. As defesas "se tornaram mais uma 'ação entre amigos' do que propriamente bancas examinadoras, aprovando trabalhos que não mereciam a 'cidadania acadêmica"'. Ou seja, as pesquisas são avaliadas, muitas vezes, apenas pelo lado sentimental ou emocional, sem levar em consideração a rigorosidade e a legitimidade necessárias a um trabalho acadêmico. $\mathrm{E}$ assim os resultados de tais pesquisas acabam nas bibliotecas, tornando-se exclusivamente formadores de opinião dos profissionais da área.

Outro problema apontado é a ausência de diálogo com teorias divergentes. Os pesquisadores ficam presos a seus referenciais teóricos, como se fossem inquestionáveis, não oportunizando a troca, a crítica e a construção possível por ações comunicativas. Talvez a discussão esteja realizando-se por vertentes muito independentes umas das outras, bloqueando a possibilidade de uma aprendizagem mútua e mais alargada. Afinal, como afirma Von Zuben, "os paradigmas estão de tal modo interiorizados em nossa mente, em nossa vida cotidiana, que constituem,

2 Tais manifestações serão esclarecidas ao longo do artigo. 
muitas vezes, mais um freio do que um auxílio para a busca ou compreensão do novo" (2003, p. 71). Não se trata de misturar dados das diferentes abordagens para extrair daí o resultado, criando um novo quebra-cabeça, mas "no sentido de uma melhor compreensão, que é essencial à noção da construção do conhecimento científico e confiável sobre o mundo" (Bannell, 2006, p. 130). É aqui que brota o questionamento: "Será que a cultura não oferece dispositivos teóricos capazes de auxiliar a compreensão do outro e a colocação da alteridade como condição imprescindível para a ocorrência do fenômeno da compreensão e da produção do conhecimento?" (Trevisan, 2006, p. 129). Sem dúvida, podemos concordar com o diagnóstico de Von Zuben: "Há como que um déficit de racionalidade de insuficiência da nossa matriz epistêmica em 'dar conta’ desse fenômeno, o 'outro' da razão” (2003, p. 53). Mas, como identidade que pertence a uma mesma humanidade, a cultura possui dispositivos teóricos, um manancial, um verdadeiro estoque ou reservas de sentidos para propiciar o entendimento das diversas formas de vida. Essa crença também é compartilhada por Von Zuben (idem, ibidem):

Devemos reconhecer, no entanto, que a especificidade da civilização ocidental é essa capacidade de se colocar em questão e de auto-criticar-se. Embora tenha cometido atrocidades em sua história, o Ocidente instituiu essa capacidade de contestação interna de submeter à crítica suas instituições e suas próprias ideias, tudo isso em nome de uma linguagem racional e razoável entre seres humanos, de um diálogo que permanece aberto e que rejeita todo dogma decisivo e último.

E ainda outra causa é que as pesquisas têm-se realizado em geral na tentativa de transformar apenas contextos particulares. Com o discurso da transformação particular, muitos têm-se ocupado do propósito de resolver problemas individualizados, esquecendo que a particularidade é parte integrante da totalidade. É pertinente a análise crítica de Duarte a esse respeito, quando percebe que: "O mergulho do pesquisador no cotidiano escolar deveria ocorrer livre de teorizações e da ansiedade pelas sínteses. A difusão desse tipo de concepção fez com que as teses e as dissertações se tornassem cada vez mais meras descrições e narrativas" (Duarte, 2010, p. 70). Desse modo, esquece-se que o propósito da ciência é o da construção coletiva do conhecimento. Ou seja, a finalidade da pesquisa científica não é dar conta de um ente particular sem que esse fenômeno possa ser utilizado como reflexão para compreender outros casos semelhantes. É nesse sentido que Duarte conclui sua crítica dizendo:

As descrições, no melhor dos casos, chegam a ser organizadas por meio de categorias empíricas e provisórias, desvinculadas de uma teoria que justifique sua adoção e seu uso, categorias essas quase sempre tomadas de empréstimo, de maneira fragmentada, eclética e pragmática, de alguns autores escolhidos a título de referencial teórico. As narrativas não fogem a esse perfil, mudando apenas a "metodologia" adotada. (idem, ibidem) 
Mesmo quando a teoria é utilizada, ocorrem diversos problemas no manejo das fontes. No intuito de não parecer hermético, com um discurso dirigido somente a especialistas, certos trabalhos acabam simplificando demasiadamente a compreensão do assunto. Longe de oferecer uma mediação compreensiva da discussão em pauta, ou do(s) autor(es) trabalhado(s), trazendo-o(s) hermeneuticamente para falar com o nosso tempo, essas pesquisas buscam apenas "transitar" por uma teoria, pelo(s) pensador(es) escolhido(s), ou mesmo pela temática selecionada, sem fazer as paradas obrigatórias, enfrentar obstáculos e refletir detalhadamente sobre sua complexidade. Na pesquisa buscamos, em geral, qualificar uma discussão para que tenhamos subsídios, com suficiente maturidade e compreensão do assunto, a fim de intervir com maior probabilidade de êxito. Mas para isso, como já ensinava o grande mestre Paulo Freire, é preciso problematizar a situação, interrogá-la, para abalar as certezas prévias e provocar a reflexão, de modo que, diante de tal abalo, provocação, ou mesmo irritação, as pessoas sejam incentivadas de alguma forma a procurar saídas, seguindo seus próprios critérios e situações concretas vividas. No entanto, sem passar pelo crivo teórico de grande(s) mediador(es) da compreensão, dificilmente esse caminho será percorrido, ficando a investigação a dever ulteriores desenvolvimentos.

Tais causas têm impedido o avanço da produção sobre a formação e dificultado cada vez mais o avanço das teorias e práticas docentes. Assim, a área vem perdendo credibilidade, sendo acusada de oferecer discussões superficiais, distantes da realidade e com pouca contribuição teórico-prática. De outra maneira, a hermenêutica reconstrutiva apresenta-se como uma perspectiva teórica a ser discutida no tratamento da formação de professores, pois tem como recurso fundamentador a possibilidade de fazer com que a multiplicidade interpretativa possa interagir de modo comunicativo. Por meio da aceitação e da negação de argumentos, a aprendizagem é alcançada quando múltiplas vozes se empenham no mesmo foco solucionador de um dado problema. Parece-nos que as problemáticas acerca da formação do professor apontam para a necessidade de uma reconstrução conceitual que, embora aproximativa, possa colocar-se como guia para uma solução mais ampliada diante da mesma reivindicação: a qualidade educacional. Ela coloca-se como recurso, tendo em vista sua capacidade de descentralizar a perspectiva do pesquisador solitário, que chega a compreensões por seu próprio viés teórico. Em vez disso, no enfoque comunicativo, diferentes pesquisadores entram em discussão na tentativa de alcançar soluções, não apenas rápidas e contextualizadas, mas especialmente sustentáveis e abrangentes. A proposta é produzida na contingência como expediente para a produção de novos proferimentos, não para ser mecanicamente aplicados às diferentes realidades, mas sobretudo para ser reconstruídos diante das necessidades das práticas vividas, já que "el ámbito objetual de las ciencias sociales comprende todo lo que puede caer bajo la descripción 'elemento de un mundo de la vida"' (Habermas, 2003a, p. 154). 


\section{A ABORDAGEM DA HERMENÊUTICA RECONSTRUTIVA}

Assim como a hermenêutica tradicional e a dialética, a hermenêutica reconstrutiva contesta a transposição da ciência tradicional para as ciências sociais e aponta para um conhecimento dependente de um processo tanto objetivo quanto subjetivo, defendendo a ideia de que o mundo não é acessível independentemente dos sujeitos que o produzem. No entanto, diferentemente de ambas, Habermas propõe uma hermenêutica como atitude metodológica para as ciências sociais, apostando em uma versão transcendente, mas ao mesmo tempo dependente das abordagens empíricas, dizendo que as regras, os valores e atitudes que constituem o sujeito são tão participantes da ciência quanto o que é possível apreender pela observação. Em Conhecimento e interesse, o autor defende a ideia de que o sujeito do conhecimento tem compromisso com os processos de aprendizagem dos quais depende a reprodução do mundo da vida. Segundo ele, toda ciência supõe uma relação com os interesses humanos, que são as condições de possibilidade das experiências vividas, experiências essas constituidoras dos objetos. Ou seja: a compreensão da realidade é vista a partir de interesses resultantes da ação com a natureza e dos ditames do sistema social, sendo esses garantia da compreensão da vida e da história. Desse modo, a razão interessada é condição de possibilidade do conhecimento (Habermas, 1987a).

Ainda nesse livro, o autor apresenta três tipos de interesse: interesse técnico regulado pela objetividade (seguido pelas ciências empíricas); interesse prático regulado pela intersubjetividade (seguido pelas ciências histórico-hermenêuticas); e o interesse emancipatório regulado pela reflexão crítica (seguido pelas ciências críticas). Habermas segue o interesse pela emancipação, percebendo na autorreflexão da razão a possibilidade de assegurar ao homem a capacidade de superar as formas de dominação. A experiência da autorreflexão, a partir das experiências práticas da vida, é condição necessária para que a ciência considere as necessidades da vida humana. Por seu intermédio, o pesquisador pode suprimir as estruturas coercitivas subjacentes à relação sujeito e objeto e assumir postura crítica (Habermas, 1987a).

Habermas discute assim as condições de possibilidade do conhecimento, apoiando-se, para isso, na filosofia transcendental kantiana. No entanto, ele procede uma inversão desse transcendental, substituindo a síntese da consciência sobre o objeto pela síntese das experiências vividas, que logo se colocam como interações linguísticas. Não se trata a priori da consciência de Kant, mas de algo constituído pelos interesses orientadores do conhecimento. Não é nem um elemento da consciência, nem da pura empiria, mas da experiência prática coletiva. A proposta é a de um transcendental transformado, uma virada pragmática do transcendental kantiano em que a experiência é constituída no contexto da ação. Em suma, trata-se de um conhecer crítico que se torna realizável por uma autorreflexão possível que perpassa a experiência coletiva. 
O objetivo de Habermas foi realizar uma crítica à ciência tradicional e retomar a autorreflexão por ela recusada. No entanto, a partir das discussões que incorporou posteriormente - as teses de Kuhn, a teoria dos jogos de linguagem de Wittgenstein e o falibilismo popperiano, entre outros -, a operação crítica cedeu lugar à operação construtiva de elaboração da teoria da ação comunicativa. Enquanto em Conhecimento e interesse o autor trata da gênese do sentido oferecida pelos interesses orientadores do conhecimento, na Teoria da ação comunicativa vai falar da possibilidade de validação discursiva dos enunciados. Habermas percebe que as teorias só podem ser elaboradas por condições de argumentação. Ele compreende que a razão não deve abrigar

[...] esperanzas ontológicas de conseguir teorías substantivas de la naturaleza, la historia, la sociedad etc., ni tampoco las esperanzas que abrigó la filosofía transcendental de una reconstrucción apriórica de la dotación transcendental de un sujeto genérico, no empírico, de uma conciencia en general. (Habermas, 2003a, p. 16)

Passa, então, a defender a ideia de que a unidade razão não pode ser percebida a não ser na multiplicidade de vozes, que só acontece quando falante e ouvinte saem dos limites da subjetividade em favor da intersubjetividade justificada. A base justificadora passa a ser a relação intersubjetiva de obrigação mútua que permite o desempenho comunicativo sem perturbações.

O autor propõe, a partir daí, a experiência de gerar consensos nos quais diversos participantes devem superar a subjetividade inicial de seus respectivos pontos de vista. A partir de uma comunidade de opiniões racionalmente motivada, tem-se a unidade do mundo objetivo e a intersubjetividade do contexto em que se desenvolvem suas vidas. Há uma simbiose nesses processos, de tal modo que: "en la acción comunicativa, incluso el inicio de la interacción se hace depender de que los participantes puedan ponerse de acuerdo en un enjuiciamiento intersubjetivamente válido de sus relaciones con el mundo" (idem, p. 152). A partir de um acordo sobre o mundo objetivo, é possível alcançar uma interação rumo à validade intersubjetiva, em que a força do melhor argumento é elemento crucial da tomada de decisão. Ou seja, o consenso é possível quando os participantes, depois de uma discussão hipotética, obtêm aceitabilidade mútua acerca do argumento mais bem justificado.

A verdade passa a ser um problema de argumentação racional que tem como fundo o mesmo mundo objetivo. Ela está fundada no consenso a que se chega depois de um discurso fundado em argumentos racionais. Habermas faz a diferenciação simbólica entre mundo da ação e mundo do discurso para tratar da questão do conhecimento. Tudo para ele é linguagem, no entanto, essa linguagem comporta-se de maneira diferente nos dois mundos. $\mathrm{Na}$ ação, as afirmações não são nem verdadeiras nem falsas, apenas adequadas ou não. Somente quando não são adequadas, são questionadas quanto às razões e só então levadas para o discurso 
(o questionamento é feito no mundo da ação), momento em que se colocam de forma hipotética até a validação. No discurso, em que o critério maior é que os sujeitos (competentes linguísticos) estejam dispostos a chegar a um consenso com o outro, devem-se seguir as pretensões de validade e discutir até que se esgote a argumentação. Aqui o critério de verdade (validade) é sempre o consenso. A verdade não é sinônimo da razão comunicativa, mas a própria razão comunicativa - assim como a crítica da razão, para Kant, coloca-se com instância de possibilidade para a busca da afirmação da verdade (validade). No entanto, não se trata de uma verdade absoluta, pois um novo consenso pode surgir numa nova situação de discurso. Habermas percebe que o processo de formação do consenso é algo infinito, ou seja, ele é um moderador que nunca pode ser esgotado. Segue um esquema ilustrativo dessa discussão:

Esquema 1- Processo racional de formação do consenso

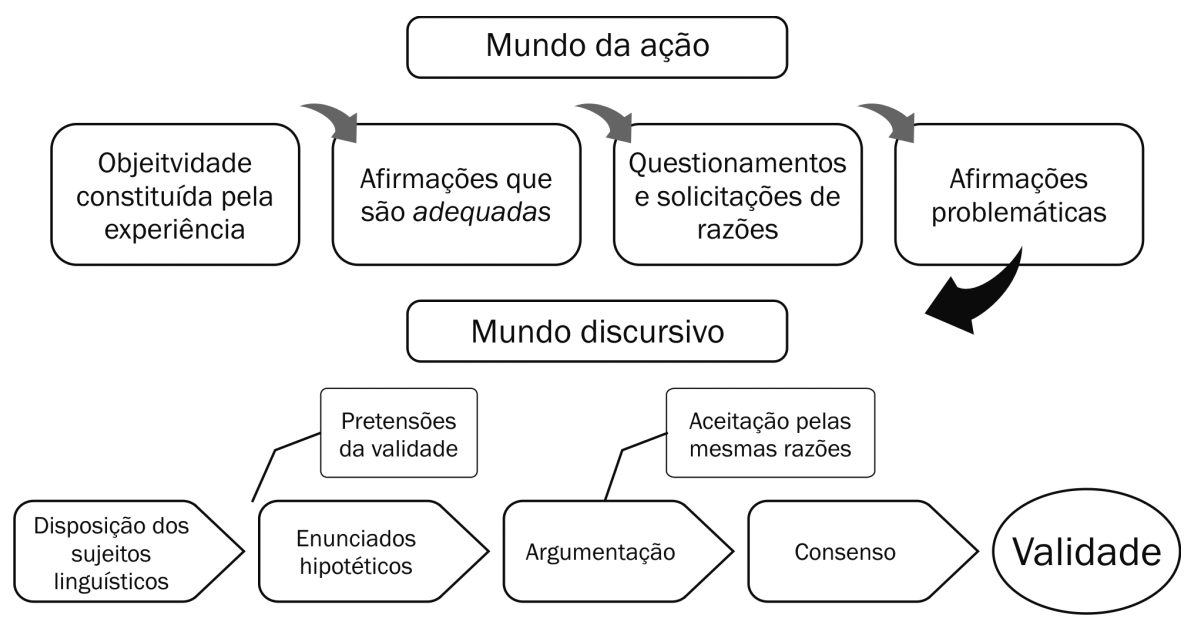

Como mostra o esquema anterior, o critério por excelência da verdade é a justificação racional no âmbito do discurso em que todos os participantes apresentam seus enunciados baseados em pretensões de validade aceitas no grupo. Os participantes defendem suas pretensões de validade (verdade, veracidade e retitude) apresentando razões por meio de argumentos até atingir o consenso (aceitação pelas mesmas razões), sendo os enunciados determinados na relação com o objeto definido. Para que a comunicação esteja endereçada ao entendimento, os falantes competentes precisam pretender a verdade do conteúdo proposicional, a retitude da norma e a veracidade das expressões. Habermas (1997, p. 198) afirma: "todo agente, al actuar comunicativamente, no puede menos de suponer el cumplimiento de pretensiones universales de validez". Tais pretensões de validade colocam-se como possibilidade corretiva da linguagem diante de suas diversas modalidades. Assim, servem 
[...] de hilos conductores para escoger los puntos de vista teóricos desde los que fundamentan los modos básicos de empleo de lenguaje, o funciones del lenguaje, y llevar a cabo una clasificación de la variedad de actos de habla que nos ofrecen las distintas lenguas particulares. (Habermas, 2003a, p. 358)

Por esse caminho, ele defende a tese de que o entendimento se alicerça no reconhecimento intersubjetivo das pretensões de validade, compreendendo as razões de escolha do falante que busca entender-se com o ouvinte. Sendo assim: "el valor real del entendimiento consiste, pues, en un acuerdo alcanzado comunicativamente, que se mide por pretensiones de validez y que viene respaldado por razones potenciales" (idem, p. 380). A linguagem orientada ao entendimento exige dos participantes o cumprimento de tais pretensões que em princípio estão sujeitas a críticas. Na ação comunicativa, os participantes são dependentes uns dos outros; o falante depende da afirmação ou da negação do ouvinte. Assim, deve-se cumprir "las condiciones necesarias para que un oyente pueda tomar postura con un sí frente a la pretensión que a ese acto vincula el hablante" (idem, p. 382).

Os significados não são determinados pelas condições de verdade existentes no mundo, mas pelas pretensões de validade que são dependentes das razões que o falante oferece para que sejam aceitas. As pretensões só são aceitas quando não existem razões para renunciar a elas e quando temos razões suficientes para reconhecê-las. A verdade é sempre uma pretensão de validade acatada por argumentos racionais. $\mathrm{Na}$ ação comunicativa, só são aceitas as declarações vinculadas às pretensões de validade; são excluídas quaisquer tentativas de ação estratégica. De acordo com Habermas (idem, p. 393):

[...] la intención comunicativa del hablante comprende, pues, a) el realizar un acto de habla que sea correcto en relación con el contexto normativo dado, para poder con ello establecer una relación interpersonal con el oyente, que pueda considerarse legítima; b) el hacer un enunciado verdadero (o presuposiciones de existencia ajustadas a la realidad) para que el oyente pueda asumir y compartir el saber del hablante; y c) el expresar verazmente opiniones, intenciones, sentimientos, deseos etc., para que el oyente pueda fiarse de lo que oye.

O entendimento funciona como mecanismo de coordenação da ação comunicativa em que os participantes reconhecem intersubjetivamente as pretensões devalidade que se negociam entre uns e outros. A pretensão de validade do falante deve, em princípio, ser acessível ao ouvinte, sendo o sucesso da ação comunicativa dependente das condições em que os participantes desenvolvem seus planos a partir de uma situação comum. Do desempenho das pretensões de validade, podem-se originar: uma fundamentação descritiva, uma fundamentação normativa, uma fundamentação avaliativa e uma fundamentação expressiva. Segundo Habermas (idem, p. 65): 
[...] la fundamentación de enunciados descriptivos significa la demostración de la existencia de estados de cosas; la fundamentación de enunciados normativos, la demostración de la aceptabilidad de acciones o de normas de acción; la fundamentación de enunciados evaluativos, la demostración de la preferibilidad de estos o aquellos valores; la fundamentación de enunciados expresivos, la demostración de la transparencia de las autopresentaciones.

Tais fundamentações são intersubjetivamente comprovadas, não são certezas vividas. Trata-se de um deflacionamento pragmático de Kant em que a “análise transcendental' significa a busca de condições supostas universais, mas apenas de facto inevitáveis que devem ser preenchidas para que determinadas práticas ou operações fundamentais possam ocorrer" (Habermas, 2004, p. 18). Assim, se para Kant a verdade dos enunciados é garantida pela validade objetiva das condições da experiência (consciência), para Habermas a constituição de experiência (vivida) não é suficiente. A verdade dos enunciados deve ser garantida pelo discurso racional. A objetividade é determinada pelo êxito na experiência com o mundo e a verdade pelo sucesso discursivo. Na Teoria da ação comunicativa, a teoria epistemológica aparece destituída de qualquer sustentação na realidade. A verdade restringe-se às situações de comunicação que acontecem por meio de razões e argumentos. A verdade conserva uma referência à realidade, mas essa referência não constitui papel na justificação. A realidade coloca-se apenas como coerência entre os enunciados numa situação linguística. Só temos interpretações diferentes porque o fenômeno é o mesmo. Segundo as palavras de Habermas (1987a, p. 339), as teorias "não podem ser elaboradas e desenvolvidas senão sob (as) condições da argumentação e, ao mesmo tempo, nos limites da objetivação anterior, própria a eventos dos quais podemos ter experiências".

Os participantes do discurso são sempre sujeitos capazes de falar e agir, devem ter competência linguística. Essa competência é determinada por regras que adquirimos no processo de socialização e oferecem sentido à conversação. Todos devem pretender chegar a um entendimento com outro sobre algo no mundo. $\mathrm{O}$ entendimento é o telos da comunicação. O importante não é a experiência subjetiva, mas as relações que se estabelecem na comunicação quando os indivíduos buscam entender-se sobre algo. Para Habermas (1997, p. 418):

[...] llamo acción comunicativa a aquella forma de interacción social en que los planes de acción de los diversos actores quedan coordinados por el intercambio de actos comunicativos, y ello haciendo una utilización del lenguaje (o de las correspondientes manifestaciones extraverbales) orientada al entendimiento.

$\mathrm{O}$ entendimento persegue as intenções comunicativas que o falante alcança, fazendo-se entender perante o ouvinte. A intenção do falante avista as consequências positivas e negativas que sua ação pode provocar no ouvinte. Dessa maneira, ainda segundo o argumento de Habermas (idem, p. 199), 
[...] el entendimiento es, pues, un proceso que trata de superar la no compresión y el malentendido, la no veracidad entre a si y frente a los demás, la no concordancia en suma, y ello sobre la base común de pretensiones de validez que se enderezan a un reconocimiento recíproco.

$\mathrm{O}$ foco do entendimento faz que o ouvinte aceite o ato de fala e fundamente "un acuerdo que se refiere, de un lado, al contenido de la emisión y, de otro, a las garantías inmanentes al acto de habla y a las obligaciones relevantes para la interacción posterior" (Habermas, 2003a, p. 379). Mas, para entender a posição da hermenêutica reconstrutiva diante das discussões sobre a formação de professores, propomos a seguir a reformulação de algumas ideias para melhor esclarecer a discussão.

\section{A HERMENÊUTICA RECONSTRUTIVA NA FORMAÇÃO DO PROFESSOR}

A partir da inserção dos discursos da formação no universo da abordagem reconstrutiva, as pesquisas passam a ser realizadas levando em consideração a categoria do (diálogo com o) outro em toda a sua radicalidade, isto é, dialogando com o coletivo, com outras discussões historicamente já realizadas, com os modelos de formação existentes, com diferentes autores, com diferentes teorias, enfim, com as múltiplas compreensões sobre o mesmo assunto. Trata-se de uma instância que pode oferecer contribuições na medida em que busca "reforçar a possibilidade de existência das diferentes abordagens pelo procedimento comunicativo, revertendo assim diversos problemas ocasionados pela fragmentação das investigações" (Devechi; Trevisan, 2010, p. 149). Ou seja, não se trata simplesmente da interpretação de observadores que buscam entender os sentidos de uma manifestação simbólica, nem a busca de explicações a partir da perspectiva da objetividade material e muito menos o acomodar-se à pluralidade infinita das interpretações. Antes, porém, busca-se validar proposições enunciadas por participantes de uma interação que orientam suas ações pelo telos do entendimento. O pesquisador abandona desse modo os dogmatismos do perspectivismo interpretativo, da objetividade que apaga os sujeitos do discurso, ou mesmo as reflexões puramente solitárias, para entrar no esforço de se chegar a uma interpretação suscetível de consenso, em que "una pretensión de validez lleva implícita la afirmación de que algo es digno de ser reconocido" (Habermas, 2003a, p. 189). O conhecimento passa a ser legitimado não pelo intérprete observador, nem pelo crítico-objetivo e muito menos pelo militante do dissenso, mas pela atitude de afirmação ou negação dos proferimentos do participante de uma interação comunicativa.

Dessa maneira, diante da diversidade das necessidades e dos interesses educacionais, é possível investigar não somente sobre o que está presente no conceito de formação, ou sobre algo que tende exclusivamente para ele, mas que aposta na reconstrução de argumentos com os diversos conceitos e discursos atualizados, ou mesmo que estão sendo gestados. Nesse sentido, Habermas afirma que "el momento 
exploratorio, orientado al conocimiento, no puede separarse del momento creativo, constructivo, orientado hacia la producción de un consenso" (idem, p. 175).

A partir dos propósitos de Habermas, essa abordagem poderia então contribuir para a formação de professores no intuito de possibilitar encarar os problemas apontados por meio da comunicação racional. Nessa perspectiva, ela daria conta do resgate da memória, pois as pretensões de validade apresentadas no discurso devem estar alicerçadas no saber acumulado no universo cultural que, para Habermas, é sempre dependente do mundo da vida e, portanto, linguístico. Ainda sobre o mundo da vida, ele diz o seguinte:

O significado de esta expresión puede aclararse intuitivamente por referencia a aquellos objetos simbólicos que generamos cuando hablamos y actuamos, desde las manifestaciones inmediatas (como son los actos de habla, las actividades teleológicas, etc.) pasando por los sedimentos de tales manifestaciones (como son los textos, las tradiciones, los documentos, las obras de arte, las teorías, los objetos de la cultura material, los bienes, las técnicas, etc.) hasta los productos generados indirectamente, susceptibles de organización y capaces de estabilizarse a sí mismo (como son las instituciones, los sistemas sociales y las estructuras de la personalidad). (idem, p. 154)

Ou seja, os argumentos sobre a memória são racionais, neste caso, porque têm relação com algo já experienciado no mundo vivido e que hoje se encontra consolidado nas tradições culturais.

A hermenêutica reconstrutiva atenderia também à questão da validação das pesquisas, pois está fundada no telos do consenso. Ou seja, o conhecimento só pode ser considerado válido porque está fundado no acordo pelas mesmas razões. Dado que a legitimidade do saber, na perspectiva exclusiva da relação sujeito e objeto, entrou em declínio, é preciso repensar a dinâmica de validação dos conhecimentos mediante acordos considerados legítimos ou não pelos sujeitos implicados. Seria resolvida, assim, a questão da falta de diálogo, porque os consensos aí estabelecidos estão necessariamente alicerçados na conversação. A exigência de discussão sobre as pretensões de validade impediria que ela ficasse presa aos limites das intenções ou da opinião do sujeito intérprete ou do mundo objetivo, como algo pertencente aos mundos subjetivo ou objetivo. Para Habermas (2003a), o seguimento de pretensão de validade é uma forma de submeter as supostas perspectivas de êxito a uma crítica que se embasa em nosso saber do mundo vivido e em nossa comparação entre o mundo fático e o mundo discursivo. $\mathrm{O}$ pesquisador precisa argumentar ante o outro para que sua proposta seja validada. Nesse sentido, diz o autor que "todo consenso descansa en un reconocimiento intersubjetivo de pretensiones de validez susceptibles de crítica, y para ello hay que suponer que los sujetos que actúan comunicativamente son capaces de criticarse recíprocamente" (idem, p. 167-168). A comunicação é o espaço da troca e da construção entre diferentes perspectivas que buscam equacionar os problemas encontrados. 
A proposta também acolheria a necessidade de pensar a particularidade dentro da totalidade, sendo o objetivo maior não só atender um campo específico, mas tratá-lo como algo constituinte do universo argumentativo das práticas universais. Nesse sentido, ainda segundo Habermas (2003a, p. 192), "el proceso de entendimiento como negociación cooperativa de definiciones compartidas de la situación, posee en un determinado sentido una validez universal". Para o autor, o atendimento da multiplicidade das perspectivas exige, como base, um princípio de universalização que, embora fraco, trate das regras reconhecidas por todos e permita acordos cada vez mais amplos.

Em se tratando da produção de conhecimento na área específica da formação de professores, que, como dissemos anteriormente, tem se sustentado por diferentes interpretações diante de uma ampla rede de significados, preocupações e manifestações geradas linguisticamente, falar "com" a formação de professores parece ser o recurso mais próximo do alcance da produção que atende, de forma qualitativa, as múltiplas expectativas do professor em relação à sua formação. $\mathrm{E}$ isso ocorre porque, conforme salienta, "la comprensión de un significado es una experiencia imposible de hacer solipsísticamente, por tratarse de una experiencia comunicativa. La comprensión de una manifestación simbólica exige esencialmente la participación en un proceso de entendimiento" (idem, p. 159).

Não se busca logicamente propor a defesa de uma teoria salvadora, ${ }^{3}$ mas antes explicitar a importância, a necessidade e a possibilidade de colocar as diferentes concepções em questão, a fim de promover pontos de aproximação argumentativa que podem permitir e/ou contribuir para a gestação de uma educação de qualidade almejada por todos. Pensar a educação e, especificamente, a formação do professor, a partir da lógica comunicativa, torna-se uma tarefa complexa, pois parece seguir na contramão de determinados caminhos adotados em grandes fóruns acadêmicos. Tendo uma dimensão comum para pôr em questão os diferentes discursos, seria evitado o fechamento em nichos cada vez mais especializados ou específicos, que são próprios de cada GT (Grupo de Trabalho) ou GE (Grupo de Estudo). A preocupação com os destinos coletivos da área não ficaria restrita ao tratamento de questões de cunho administrativo ou de trato pelo viés metodológico simplesmente. Pelo contrário, a

3 Existem controvérsias no interior da discussão da teoria da ação comunicativa que nos impedem de qualquer crença nesse sentido. $\mathrm{O}$ próprio Habermas admite equívocos no decorrer da formulação de sua teoria, concordando com muitas objeções que lhe foram apresentadas por seus críticos. Mas isso, longe de desacreditar seu trabalho, tem corroborado com ele, porque demonstra que o próprio autor está conseguindo ser, no fundo, fiel ao que ele mesmo preconiza, ao dialogar com o diferente e aprender no contato com o outro, reconstruindo constantemente seus argumentos. Sobre isso, ver o livro de A. Guidens et. al., Habermas y la modernidade, Madrid, Cátedra, 1994, mais especialmente o artigo de Habermas, "Cuestiones e contracuestiones". E ainda o livro de Luiz Moreira (Org.), Com Habermas, contra Habermas: direito, discurso e democracia, São Paulo, Landy Editora, 2004. 
luta se concentraria em desenvolver estruturas de apoio para que a educação possa "conquistar um ethos cada vez mais universal, no qual as diferentes perspectivas teóricas poderão, enfim, dialogar, sem que isso implique o abandono de seus locus específicos" (Devechi; Trevisan, 2010, p. 160).

Essa é uma abordagem difícil de ser compreendida pela simples observação e interpretação, pois envolve sempre um saber intuitivo e pré-teórico que pode acarretar confusões, exigindo do pesquisador, além de uma postura de observador crítico e intérprete, a de falante e ouvinte, ou seja, reclama uma relação de esforço na participação do entendimento do outro. É nesse sentido que Habermas diz que "el intérprete tiene que conocer las condiciones de su validez; tiene que saber bajo que condiciones es aceptable la pretensión de validez vinculadas a ella, es decir, bajo que condiciones tendría que ser normalmente reconocida por un oyente" (2003a, p. 163). A ideia é que o pesquisador possa participar de uma comunidade racional de comunicação e validar seus argumentos no confronto e em acordo com a objetividade das pretensões de validade, prevenindo enganos e corrigindo mal-entendidos.

\section{CONCLUSÕES}

A hermenêutica reconstrutiva pode ser compreendida como uma abordagem teórica importante para as investigações sociais e educacionais e, no caso da presente discussão, para tratar da formação atual do professor inserida nas contingências de suas demandas. Apresenta-se com o ensejo de produzir uma teorização dialógica, histórica, crítica e confiável encaminhada à formação voltada a uma qualificação mais ampla, com a atitude de lidar com as exigências dos contextos particulares sem abandonar a possibilidade de contribuição ao universal do qual faz parte. E isso ocorre porque dar conta da singularidade jamais pode ser sinônimo do abandono da universalidade, pois esta é pressuposto da produção evoluída do conhecimento, fundamental para o sucesso dos próprios campos específicos. Por ser parte constituinte do universal, a singularidade tem responsabilidade em atendê-lo. É um compromisso circular entre o singular e o universal respeitado por sua dinâmica interna, dado que a particularidade deve somar na contribuição ao processo de discussão racional orientado para o todo e vice-versa.

$\mathrm{Na}$ medida em que os pesquisadores de diferentes abordagens teóricas se comprometem mais enfaticamente com essa forma de comunicação racional, para deliberar sobre o que pode ou não legitimar a discussão da formação de professores, pode-se, talvez, avançar bem mais a teorização sobre o assunto e, por consequência, alcançar propósitos mais bem-sucedidos do que revelam os consensos estabelecidos até o momento. Se, em Kant, os conhecimentos deviam passar pelo crivo da crítica da razão pura, para Habermas trata-se de buscar sua validação pelo exercício da crítica da razão prática, isto é, de uma razão comprometida com o exercício hermenêutico do diálogo, não como opção metodológica exclusivamente, ou seja, como mais um método posto à disposição dos educadores, mas como polo do entendimento possível. 
Sendo assim, abandonaríamos posturas sectárias ou autorreferentes preocupadas em seguir modelos adotados unilateralmente, como os que buscam suporte unicamente nas pesquisas empíricas para definir o significado de "bom professor". A conceituação do que é ser um bom professor não se esgota, por exemplo, no que os alunos eventualmente pensam num dado momento sobre o assunto. Este, sem dúvida, representa um indicador importante a ser levado em consideração no processo comunicativo, no entanto ele não pode ser a única voz. É preciso lembrar aqui o episódio em que Theodor W. Adorno se confrontou com o interesse de alguns alunos por estes interromperem sua aula num protesto na universidade. ${ }^{4} \mathrm{Ou}$ de Max Weber, quando não hesitou em defender, diante dos tribunais, um aluno que fora acusado de desacato na universidade. ${ }^{5}$ Se esses alunos, ou mesmo outras pessoas participantes desses episódios, fossem auscultados no momento do confronto, teríamos certamente um diagnóstico diferente sobre o assunto, caso esse levantamento fosse realizado a partir de outros referenciais, com outras pessoas, ou mais tarde, quando esses fatos foram mais bem explicitados ou discutidos.

Portanto, cremos ser preciso categorizar a formação do professor em seu contexto comunicativo ampliado, o qual abre a discussão para um leque mais vasto e diversificado de compreensão dos problemas. O referente extraído das pesquisas empíricas deve ser repensado e reconstruído conceitualmente no confronto e em acordo com o saber do mundo da vida como um todo, pesando as razões prós e contras sua manifestação, e não apenas as que o abalizam. Isso significa que tais argumentos emergentes dos pontos de vista dos próprios implicados são referidos aos propósitos e opiniões dos outros, sejam esses alunos, seus pares, membros da comunidade escolar ou acadêmica, sem esquecer o confronto com o conhecimento acumulado sobre o tema disposto pela tradição cultural em toda a sua amplitude. Poderíamos ter nesse sentido uma compreensão mais fundamentada do tema não "sobre", nem "em" e nem "para", mas "com" a formação de professores, o que pode levar, em tese, a resultados completamente opostos daqueles tomados pela consulta a um único segmento.

Desse modo, a reconstrução do campo conceitual da formação pode ocorrer, aproximativamente, na perspectiva da razão pública, buscando validar os conhecimen-

4 Em 1969, Adorno envolveu-se em uma polêmica por não ter apoiado os estudantes que interromperam sua aula, tentando continuar, dentro do instituto, os protestos que tomavam as ruas das capitais da Europa. Para conter os estudantes, Adorno acabou chamando a polícia. Ver a entrevista intitulada "A filosofia muda o mundo ao manter-se enquanto teoria”, concedida por Adorno à revista Der Spiegel (Adorno, 2003).

5 Nos invernos de 1917 e 1918, certos alunos socialista-pacifistas frequentavam sua casa, aos domingos, em Heidelberg. O jovem comunista Ernst Toller estava entre eles e frequentemente lia em voz alta seus versos. Mais tarde, quando Toller foi preso, Max Weber o defendeu perante um tribunal militar e conseguiu sua liberação, embora não tenha impedido sua expulsão da universidade (Cf. Gerth, 1982). Sobre isso, ver ainda o testemunho de Maurice Merleau-Ponty, As aventuras da dialéctica, Buenos Aires, Ed. Leviatan, s. d., p. 31. 
tos por diferentes formas de abordagem que, solidariamente, se complementam, livre da mera aceitação fática da pluralidade. Mas para isso é preciso retirar os discursos da formação do plano epistêmico regulado pelo entendimento singular, colocando sua exigência no nível do logos expandido, porque garante legitimidade à síntese do geral por sua manifestação na multiplicidade. Esse pode ser um caminho válido para que o professor venha de fato a construir sua tarefa de forma cada vez mais engrandecida e tenha, enfim, seu mérito reconhecido. Consequentemente, seu campo conceitual será recuperado, posto que passa a ser visto não apenas como expressão limitada dos propósitos de grupos, cuja importância é ressaltada enquanto manifesta no detalhe.

\section{REFERÊNCIAS}

Adorno, Theodor W. A filosofia muda o mundo ao manter-se como teoria. Lua Nova on-line, n. 60, p. 131-139, 2003. Disponível em: <http://www.scielo.br/scielo. php?script=sci_arttext\&pid=S0102-64452003000300008>. Acesso em: jan. 2011.

Alves-Mazzottı, Alda Judith. A relevância e a aplicabilidade das pesquisas em educação. Cadernos de Pesquisa, São Paulo, n. 113, p. 39-50, jul. 2001. Disponível em: <http://www. scielo.br/pdf/cp/n113/a02n113.pdf >. Acesso em: jan. 2011.

BANnell, Ralph Ings. I. Habermas e a educação. Belo Horizonte: Autêntica, 2006.

Charlot, Bernard. A pesquisa educacional entre conhecimentos, políticas e práticas: especificidades e desafios de uma área de saber. Revista Brasileira de Educação, v. 11, n. 31, p. 7-18, jan./abr. 2006. Disponível em: <http://www.scielo.br/pdf/rbedu/v11n31/ a02v11n31.pdf >. Acesso em: jan. 2011.

Devechi, Catia Piccolo; Trevisan, Amarildo. Sobre a proximidade do senso comum das pesquisas qualitativas em educação: positividade ou simples decadência? Revista Brasileira de Educação, v. 15, n. 43, p. 148-201, 2010. Disponível em: <http://www.scielo.br/pdf/ rbedu/v15n43/a10v15n43.pdf>. Acesso em: jan. 2011.

DuARTE, Newton. A pesquisa e a formação de intelectuais críticos na pós-graduação em educação. In: DuARTe, N.; Della FonTe, Sandra S. Arte, conhecimento e paixão na formação humana: sete ensaios de pedagogia histórico-crítica. Campinas: Autores Associados, 2010. Gerth, Hans H.; Mills, Wright. Organização e introdução. In: WebER, Max. Ensaios de sociologia. 5. ed. Rio de Janeiro: LTC Editora, 1982. Disponível em: <http://www. scribd.com/doc/8616150/Max-Weber-Ensaios-de-Sociologia>. Acesso em: jan. 2011.

Guiddens, A. Habermas y la modernidad. Madrid: Cátedra, 1994.

Habermas, Jürgen. Conhecimento e interesse. Rio de Janeiro: Guanabara, 1987a.

. Dialética e hermenêutica: para a crítica da hermenêutica de Gadamer. Porto

Alegre: L\&M, 1987b.

. Teoría de la Acción Comunicativa: complementos y estudios previos. Madrid:

Catedra, 1997. 
. Racionalidade e comunicação. Lisboa: Edições 70, 2002.

. Teoría de la acción comunicativa, I: racionalidad de la acción y racionalización social. Madrid: Taurus, 2003a.

. Teoría de la acción comunicativa II: crítica de la razón funcionalista. Madrid: Taurus, 2003b.

. Verdade e justificação: ensaios filosóficos. São Paulo: Loyola, 2004.

. A lógica das ciências sociais. Petrópolis: Vozes, 2009.

Hermann, Nadja. Educação e racionalidades: conexões e possibilidades de uma razão comunicativa na escola. Porto Alegre: EDIPUCRS, 1996.

Mareues, Mario Osório. Educação/interlocução, aprendizagem/reconstrução de saberes. Ijuí: Ed. UNIJUÍ, 1996.

Moreira, Luiz (Org.). Com Habermas, contra Habermas: direito, discurso e democracia. São Paulo: Landy Editora, 2004.

Merleau-Ponty, Maurice. As aventuras da dialéctica. Buenos Aires: Ed. Leviatan, s. d.

Trevisan, Amarildo Luiz. A cultura da alteridade educativa. In: Trevisan, A. L.; Tomasetti, Elisete M. Cultura e alteridade. Ijuí: Ed. da UNIJUÍ, 2006.

. Filosofia da educação: mímesis e razão comunicativa. Ijuí: Ed. da UNIJUí, 2000.

VON ZUBEN, Aquiles N. Formação de professores: da incerteza à compreensão. In: BICUDO, Maria Aparecida V. (Org.). Formação de professores? Da incerteza à compreensão. Bauru: EDUSC, 2003 (Coleção Educar).

\section{SOBRE OS AUTORES}

Catia Piccolo Viero Devechi é doutora em educação pela Universidade Federal de Santa Catarina (UFSC). Professora do Departamento de Teoria e Fundamentos da Faculdade de Educação da Universidade de Brasília (UnB). E-mail: devechi@unb.br

Amarildo LuzZ Trevisan é doutor em educação pela Universidade Federal Rio Grande do Sul. Professor do Programa de Pós-Graduação em Educação da Universidade Federal de Santa Maria (UFSM).

E-mail: amarildoluiz@terra.com.br

Recebido em janeiro de 2011

Aprovado em março de 2011 


\section{CATIA PICCOLO VIERO DEVECHI E AMARILDO LUIZ TREVISAN}

\section{Abordagens na formação de professores: uma reconstrução aproximativa do campo conceitual}

A formação de professores é tema provocativo de um debate infindável, ao mesmo tempo, porém, muito frutífero para o avanço da investigação educativa no Brasil. São muitas as pesquisas, principalmente de pós-graduação, que discutem o assunto. E não é por acaso, pois se trata de uma preocupação característica do momento histórico atual, que busca aclarar as bases teóricas da formação para que seja possível uma educação de qualidade a todos. As motivações deste estudo buscam aliar-se à urgência no enfrentamento desses problemas do campo da formação detectados nas pesquisas acadêmicas, que infelizmente têm sido tratados por vezes de forma apenas corriqueira. Porém, mais do que isso, exigiriam na verdade uma reformulação de seu campo conceitual. Em vista dessa enorme exigência, pretendemos neste trabalho cumprir uma tarefa, definida pela filosofia da educação, de maneira apenas aproximativa, propondo um olhar hermenêutico-reconstrutivo com o intuito de repensar os eventuais equívocos nos rumos do debate.

Palavras-chave: formação de professores; filosofia da educação; hermenêutica reconstrutiva; pesquisa educacional

\section{Approaches in formation of teachers: an aproximative reconstruction of the conceptual field}

The formation of teachers is a provocative subject of endless debate, but at the same time very fruitful for the advancement of educational research in Brazil. There are many educational researches, especially of post-graduate level, that conduct discussions on this subject. It is no coincidence that this happens because it is a characteristic concern of the current historical moment, which seeks to clarify the theoretical basis of the formation making possible a quality education for all. The motivations of this study seek to combine the urgency to address these problems in the field of formation of teachers identified in academic research, which unfortunately have been treated sometimes in an unexceptional way. But more than that, it would actually require a reformulation of its conceptual field. In view of this huge demand, we intend to accomplish a task in this work, defined by the Philosophy of the Education, in an approximate way, proposing an hermeneuticreconstructive view in order to rethink the possible mistakes in the course of the debate.

Keywords: formation of teachers; philosophy of education; reconstructive hermeneutics; educational research 


\section{Abordagenes en la formación de profesores: una reconstrucción aproximativa del campo conceptual}

La formación de profesores es un tema provocativo para un debate sin fin, pero, al mismo tiempo, demasiado fructifero para el avance de la investigación educativa en Brasil. Son muchas las pesquisas educacionales, principalmente de posgrado, que realizan discuciones sobre ese tema. No es al acaso que eso se sucede, pues se trata de una preocupación característica del hecho historico actual, que busca esclarecer las bases teóricas de la formación para que sea posible una educación de calidad para todos. Las motivaciones deste estudio buscan aliarse a la emergencia en el enfrentamiento de eses problemas del campo de la formación detectados en las pesquisas académicas, los cuales desafortunadamente han tratados por veces de forma solamente habitual. Pero, más que todo eso, ellos exigen en la verdad una reformulación de su esfera conceptual. Por esta grande exigencia, pretendemos, en este trabajo, cumplir una tarea, definida por la filosofía de la educación, de modo solamente aproximativa, proponiendo una mirada hermenéutico-reconstructivo con la meta de repensar los eventuales equívocos en los rumbos del debate.

Palabras clave: formación de profesores; filosofía de la educación; hermenéutica-reconstructiva; pesquisa educacional 